\title{
Johanson-Blizzard Syndrome with Short Stature
}

\author{
Khorasani EN ${ }^{1}$, Mansouri $F^{2}$
}

\begin{abstract}
Johanson-Blizzard syndrome (JBS) is a rare, sometimes fatal autosomal recessive multisystem congenital disorder featuring abnormal development of the pancreas, nose and scalp, with mental retardation, hearing loss and growth failure. It is sometimes described as a form of ectodermal dysplasia. The disorder is especially noted for causing profound developmental errors and exocrine dysfunction of the pancreas, and it is considered to be an inherited pancreatic disease. We report a ten years Irannian child with signs and symptoms suggestive of this syndrome (JBS).
\end{abstract}

Key words: Johanson-Blizzard, short stature, pancreas insufficiency, Hypotyroidism

\section{Introduction}

ohanson-Blizzard syndrome is a rare genetic disorder that characteristic with multisystem involvment particurarly: Ectodermal defects, endocrine disorder, pancreatic insufficiency and other disorders. It was named after Ann J Johanson and Robert $\mathrm{M}$ Blizzard. The paediatricians who first described the disorder in a $1971^{1,2,3}$.

\section{The Case}

We introduce a ten years old Iranian boy, product of a non consanguineous marriage, who was referred to us for short stature. His anthropometry were: weight $(24 \mathrm{~kg})$, height $(130 \mathrm{~cm})$ and head circumference $(51 \mathrm{~cm})$. According to the natal history he was IUGR at birth and was admitted to NICU because of respiratory distress. Physical examination revealed cleft palate, On auscultation of heart a holosystolic murmer (3/6) was heard at the lower left sterna border. According to the echocardiography he had VSD, and further investigation showed hypothyroidism. (TSH:12.5 $\mathrm{IU} / \mathrm{ml}$ ) and on examination had hypospadiasis and cryptorchidism noticed since seven years of age. He had constipation from birth and continued till recently despite the use of laxative drugs.

Further investigations after now (malabsorption tests, sweat test, bone age) and a careful examination; we found that he has pancreatic insufficiency and sensory neural hearing loss along
'Dr. Enayatollah Nemat Khorasani, MD, Associate Professor, Paediatric Gastrologist, Baghiyatallah University Medical of Sciences, Tehran, Iran. ${ }^{2}$ Dr. Fariba Mansouri, MD. Associte Professor, Pulmonologist, Tehran University Medical of Sciences, Tehran, Iran.

Address for correspondence:

Dr. Enayatollah Nemat Khorasani

E-mail: Khorasani@dr.com

\section{How to cite}

Khorasani EN, Mansouri F. Johanson-Blizzard Syndrome with Short Stature. J Nepal Paediatr Soc 2015;35(3):287-289.

doi: http://dx.doi.org/10.3126/jnps.v35i3.13109

This work is licensed under a Creative Commons Attribution 3.0 License.

(c) (i)

with visual problems (cornea impairment). He was treated by pancreatic enzymes (lipase:500IU/Kg up to a maximum of $50000 I U / d a y)$, levothyroxine $(50 \mu \mathrm{g} /$ day) and vitamins (VitA:5000IU/day, VitD: 400IU/day and Vit E: 1000IU/day), other supplements (Zinc:20mg/kg/day, Iron:3mg/ $\mathrm{kg} /$ day, Calcium: $1500 \mathrm{mg} / \mathrm{kg} /$ day) and acid folic (1mg/daily). His cleft palate and hypospadiasis had been repaired by previous surgery. After fallow up for one year of treatment his growth had improved (Wt;29kg, Ht:135cm, HC:54cm) and had no constipation.

\section{Discussion}

The most prominent effect of JBS is pancreatic exocrine insufficiency ${ }^{1,4,5,6,7}$. Varying degrees of decreased secretion of lipases, pancreatic juices such as trypsin, trypsinogen and others, as well 


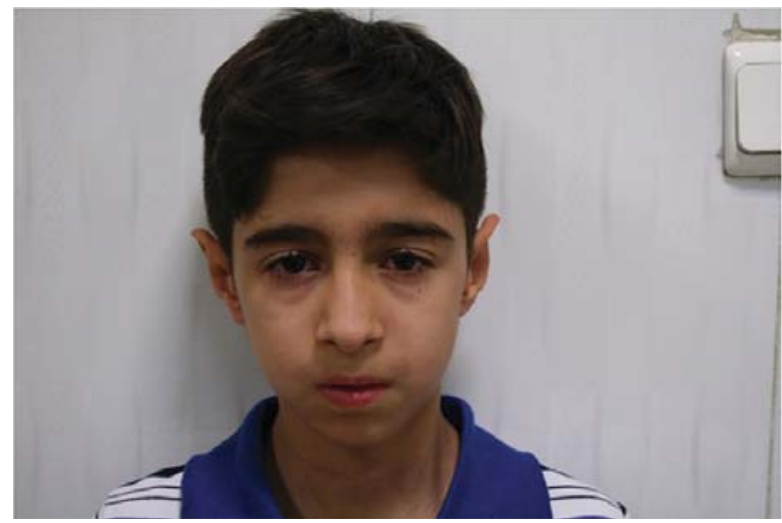

Fig 1: Showing facies of the patient (craniofacial anomalia) permission taken

as malabsorption of fats and disruptions of glucagon secretion and its response to hypoglycemia caused by insulin activity are major concerns when JBS is diagnosed ${ }^{1,3,8}$. Pancreatic exocrine insufficiency in JBS can additionally stem from congenital replacement of the acini with fatty tissue ${ }^{1,3,8,9}$. Near total replacement of the entire pancreas with fatty tissue has also been reported. This is a progressive, sometimes fatal consequence of the disorder ${ }^{9}$.

Endocrine insufficiency of the pancreas occurs with JBS, though it is sometimes less common and less pronounced than the more prominent effects on exocrine function ${ }^{1}$. Endocrine dysfunction of the pancreas often results in diabetes mellitus. Both insulin resistance and diabetes have been observed with JBS, and it is suggested that diabetes should be considered as a complication of JBS and its course ${ }^{5,7,8}$.

Endocrine abnormalities in other areas have also been present with the disorder. These include hypothyroidism ${ }^{2}$, growth hormone deficiency ${ }^{1,8}$ and hypopituitarism. Growth failure and associated short stature (dwarfism) in JBS can be attributed to growth hormone deficiency caused by diminished anterior pituitary function, with malabsorption of fats playing a subsequent role ${ }^{1,4}$.

Other abnormalities, affecting the scalp, head, face, jaw and teeth may be found with JBS. These include: ectodermal mid-line scalp defects with sparse, oddly-patterned hair growth ${ }^{2,9}$; aplasia cutis (underdeveloped, very thin skin) over the head, an enlarged fontanelle ("soft spot" on the head of young infants), microcephaly (undersized skull), prominent forehead, absence of eyebrows and eyelashes, mongoloidal eye shape, nasolacrimo-cutaneous fistulae (this refers to the formation of an abnormal secondary passageway from either the tear duct or lacrimal sac to the facial skin surface, possibly discharging fluid $)^{9}$, flattened ears, micrognathism of the maxilla and mandible (underdevelopment of the upper and lower jaw, respectively), with the maxilla more prominently affected in some cases; congenital clefting of bones surrounding the optical orbit (eye socket), such as the frontal and lacrimal bone; ${ }^{8}$ and maldeveloped deciduous teeth ("baby teeth"), with an absence of permanent teeth ${ }^{9}$.

Findings with the inner ear in JBS give explanation to the presence of bilateral sensorineural hearing loss in most patients affected by the disorder. The formation of cystic tissue in both the cochlea and vestibule, with resulting dilation and malformation of these delicate structures has been implicated ${ }^{7,9}$. Congenital deformations of the temporal bone and associated adverse anatomical effects on innervation and development of the inner ear also contribute to this type of hearing $\operatorname{loss}^{8}$.

Additional congenital anomalies, effects on other organs, and less common features of JBS have included: imperforate anus ${ }^{4}$, vesicoureteral reflux; duplex of the uterus and vagina in female infants, neonatal cholestasis of the liver, with cirrhosis and portal hypertension; ; dilated cardiomyopathy ${ }^{7,8}$, dextrocardia $^{1}$, atrial and ventricular septal defect ${ }^{1}$; low birth-weight ${ }^{7}$, failure to thrive hypotonia ${ }^{8}$; sacral hiatus (a structural deficiency of the sacral vertebrae), congenital cataracts ${ }^{9}$, and cafe-au-lait spots ${ }^{2}$.

\section{Genetics}

\section{Autosomal recessive inheritance}

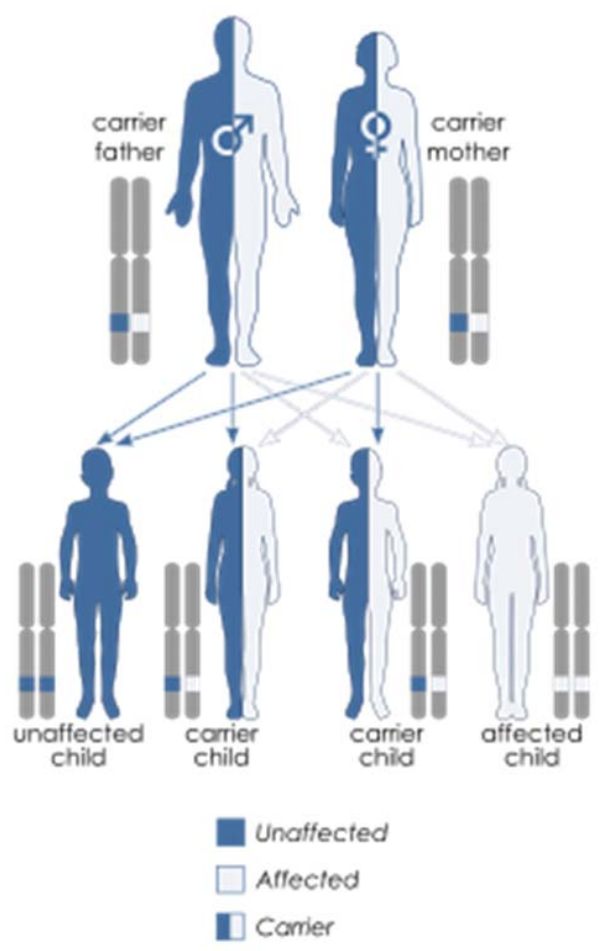


Johanson-Blizzard syndrome has an autosomal recessive pattern of inheritance ${ }^{1}$.

Johanson-Blizzard syndrome is caused by mutations in the UBR1 gene, which encodes one of several ubiquitin ligase enzymes of the $\mathrm{N}$-end rule pathway $^{1,6}$.

The UBR1 gene is located on human chromosome $15^{6}$.

\section{Treatment}

While there is no cure for JBS, treatment and management of specific symptoms and features of the disorder are applied and can often be successful. Variability in the severity of JBS on a case-by-case basis determines the requirements and effectiveness of any treatment selected.

Pancreatic insufficiency and malabsorption can be managed with pancreatic enzyme replacement therapy, such as pancrelipase supplementation and other related methods ${ }^{1,2,3}$.

Craniofacial and skeletal deformities may require surgical correction, using techniques including bone grafts and osteotomy procedures. Sensorineural hearing loss can be managed with the use of hearing aids and educational services designated for the hearing impaired ${ }^{7,8,9}$.

Special education, specialized counseling methods and occupational therapy designed for those with mental retardation have proven to be effective, for both the patient and their families. This, too, is carefully considered for JBS patients ${ }^{4,5}$.

\section{Conclusion}

This case highlights the importance of a careful and thorough physical examination in a neonate especially in SGA and IUGR, and if any congenital anomalies are found then to follow up at a later age and investigate further; in this case short stature, cranio-facial anomalies, malabsorption, malabsorption and bone age.

\section{References}

1. Alkhouri N, Kaplan B, Kay M, Shealy A, Crowe C, Bauhuber S, Zenker M. Johanson-Blizzard syndrome with mild phenotypic features confirmed by UBR1 gene testing. World J Gastroentero/2008;14(44):6863-866. doi:10.3748/ wjg.14.6863. PMC 2773884. PMID 19058315.

2. Kulkarni ML, Shetty SK, Kallambella KS, Kulkarni PM. Johanson--blizzard syndrome. Indian J Pediatr 2004;71(12):1127-129. doi:10.1007/BF02829829. PMID 15630323.

3. Zenker M, Mayerle J, Reis A, Lerch MM. Genetic basis and pancreatic biology of Johanson-Blizzard syndrome. Endocrinol Metab Clin North America 2006;35 (2):243-53, vii-viii. doi:10.1016/j. ecl.2006.02.013. PMID 16632090.

4. Sandhu BK, Brueton MJ. Concurrent pancreatic and growth hormone insufficiency in JohansonBlizzard syndrome. J Pediatr Gastroenterol Nutr 1989;9(4):535-38. doi:10.1097/00005176198911000-00026. PMID 2621533.

5. Steinbach WJ, Hintz RL. Diabetes mellitus and profound insulin resistance in JohansonBlizzard syndrome. J Pediatr Endocrinol Metabol 2000;13(9):1633-636. doi:10.1515/ jpem.2000.13.9.1633. ISSN 0334-018X. PMID 11154160.

6. Zenker M, Mayerle J, Lerch MM, Tagariello A, Zerres K, Durie PR, et al. Deficiency of UBR1, a ubiquitin ligase of the $\mathrm{N}$-end rule pathway, causes pancreatic dysfunction, malformations and mental retardation (Johanson-Blizzard syndrome). Nature Genetics 2005;37(12):1345-350. doi:10.1038/ ng1681. PMID 16311597.

7. Rosanowski F, Hoppe U, Hies T, Eysholdt U. Johanson-Blizzard syndrome. A complex dysplasia syndrome with aplasia of the nasal alae and inner ear deafness. HNO 1998;46(10):876-78. doi:10.1007/s001060050328. PMID 9846268.

8. Takahashi T, Fujishima M, Tsuchida S, Enoki M, Takada G. Johanson-blizzard syndrome: loss of glucagon secretion response to insulininduced hypoglycemia. J Pediatr Endocrinol Metab 2004;17(8):1141-144. doi:10.1515/ jpem.2004.17.8.1141. ISSN 0334-018X. PMID 15379429.

9. Daentl DL, Frías JL, Gilbert EF, Opitz JM. The Johanson-Blizzard syndrome: case report and autopsy findings. American J Med Genet 1979;3(2):129-35. doi:10.1002/ajmg.1320030203. PMID 474625. 